\title{
Relevance of solid electrolytes for lithium-based batteries: A realistic view
}

\author{
Bettina V. Lotsch ${ }^{1}$ - Joachim Maier $^{1}$ (D)
}

Received: 20 February 2017 / Accepted: 16 May 2017 /Published online: 5 July 2017

(C) The Author(s) 2017. This article is an open access publication

\begin{abstract}
Pros and cons are discussed with respect to replacing liquid electrolytes in Li-based batteries by solid electrolytes. We primarily refer to electrochemical and mechanical parameters which are the most characteristic ones in this context. Rather than giving an exhaustive overview on available solid electrolytes, we briefly discuss various systems and mainly concentrate on the recently found ultrafast sulfidebased Li electrolytes as they reflect well the positive and negative aspects of using solids for high performance batteries.
\end{abstract}

Keywords Ion conduction $\cdot$ Li batteries $\cdot$ Sulfides $\cdot$

All-solid-state cells $\cdot$ Energy $\cdot$ Electrochemistry

\section{Introduction}

As far as high power batteries are concerned there are at the moment numerous activities to replace liquid by solid electrolytes (SE) [1]. Natural reasons for this are the serious safety problems connected with the flammability of the organic liquids commonly used as electrolytes, as well as chemical shortcircuits by $\mathrm{Li}$ dendrites if elemental $\mathrm{Li}$ is used as negative electrode material. Recently various solid Li-electrolytes have been prepared which show ionic conductivities that come close to record values for the condensed phase [2-6].

It is pertinent to briefly recapitulate the history of modern batteries. The first success story was based on the lead acid accumulator using sulfuric acid as liquid electrolyte. Other

Joachim Maier

s.weiglein@fkf.mpg.de

1 Max Planck Institute for Solid State Research, Stuttgart, Baden-Württemberg, Germany very successful systems are based on aqueous hydroxide electrolytes, in particular the Ni-Cd accumulator [7, 8]. First attempts to implement solid electrolytes are in primary cells such as silver based batteries for low drain applications [9]. For heart pacemakers the safe $\mathrm{Li} \| \mathrm{I}_{2}$ cell has been employed [9]. Here, the electrolyte is a thin LiI film formed by the $\mathrm{Li}-\mathrm{I}_{2}$ contact. LiI does not exhibit a high conductivity but the electrolyte has a reasonably low resistance owing to the small thickness. More importantly even, the electrolyte is safe since self-healing takes place: Should the electrodes come into contact owing to mechanical failure, LiI is formed.

The development of powerful solid-state Li batteries has also been impeded by the lack of highly conducting electrolytes. $\mathrm{Li}_{3} \mathrm{~N}$ was a singularity in this respect, but is too reactive and of too low an electrochemical window to be useful in practical devices $[10,11]$. At about the same time very highly conducting $\mathrm{Na}$-electrolytes have been found based on $\beta$ $\mathrm{Al}_{2} \mathrm{O}_{3}$ and the NASICON structure [12-19]. While the latter ones are hardly stable with respect to $\mathrm{Na}[20,21]$, the former ones have soon been employed in the $\mathrm{Na}$-S-batteries that for a long time had been considered for electro-traction [14]. Two points are characteristic: (i) In order to ensure a good contact, an operation temperature of $300{ }^{\circ} \mathrm{C}$ was envisaged at which the electrodes are liquid. (ii) Cracking of electrolyte led to failure and terminated the commercial development of this system for electro-traction.

In the seventies pioneering work on intercalation was done, bringing single phase storage mechanisms to the fore [22-25]. At the same time Li alloys have been investigated systematically [26]. Today's triumph of Li ion batteries was only possible after high voltage cathodes such as $\mathrm{LiCoO}_{2}$ and $\mathrm{LiFePO}_{4}$ had been developed [27, 28]. Simultaneously, carbon was explored as intercalation compound as far as the anode function is concerned, avoiding dendrite formation without substantially sacrificing cell voltage [29, 30]. It soon turned out 
that owing to the comparatively low chemical diffusion coefficient of $\mathrm{Li}$ and the necessity of providing a sufficiently high electroactive mass, many-particle systems of $\mu \mathrm{m}$ or even $\mathrm{nm}$ size are required. To match this requirement, liquid electrolytes are electrolytes of choice: They provide sufficient conductivity and ensure good electrolyte/electrode contacts. If brought into contact with electrode phases of extreme chemical potential typically exceeding the thermodynamic stability window, the formation of thin passivation layers ensures kinetic stability $[31,32]$.

It is the availability of novel, highly conducting solid electrolytes for $\mathrm{Li}$ (as well as the renewed interest in $\mathrm{Na}$ for which various highly conducting solid electrolytes are available) that brought all-solid-state cells into focus [1].

In the first part of this contribution (Section 2) the pros and cons of solid electrolytes will be highlighted, while Part II (Section 3) discusses Li solid electrolytes, cf. also [33, 34], specifically the novel crystalline and highly conducting sulfide systems, in the light of the criteria addressed in the first part.

\section{Pros and cons of solid electrolytes in Li-based cells}

In this part of the paper we discuss advantages and difficulties of solid electrolytes in comparison with liquid electrolytes. From the property standpoint we need to consider (i) electrochemical properties such as ionic and electronic conductivities as well as phase transfer effects, (ii) chemical properties, (iii) mechanical properties, and (iv) thermal properties.

\subsection{Electrochemical properties}

\section{(i) Ionic Conductivity}

For a long while it seemed that Li-conductors (unlike Naconductors) do not exhibit conductivity values higher than $10^{-3} \mathrm{~S} / \mathrm{cm}$ at room temperature, an exception being $\mathrm{Li}_{3} \mathrm{~N}$ $[33,35]$. Then, in the last few years a variety of Liconductors have been synthesized with unexpectedly high values around $10^{-2} \mathrm{~S} / \mathrm{cm}$, matching the values of the best liquid electrolytes. These materials are addressed in detail in the second part of this paper.

A special problem arising in solids is the occurrence of grain boundaries or, more generally, poor grain-to-grain contacts. Negligible contributions require low porosity, structurally benign grain boundaries and absence of depletion layers. Fig. 1 shows carrier depletion at grain boundaries owing to unfavorable excess charge in the grain boundary core [36]. Naturally, a different charge can also lead to carrier accumulation. For highly conducting solids the latter effect is not worthy of mention as far as the overall conductivity is concerned, but it is a tool to improve conductivities of poor electrolytes (cf. composite electrolytes) [37]. Remarkably, by using mesoporous $\mathrm{Al}_{2} \mathrm{O}_{3}$ as

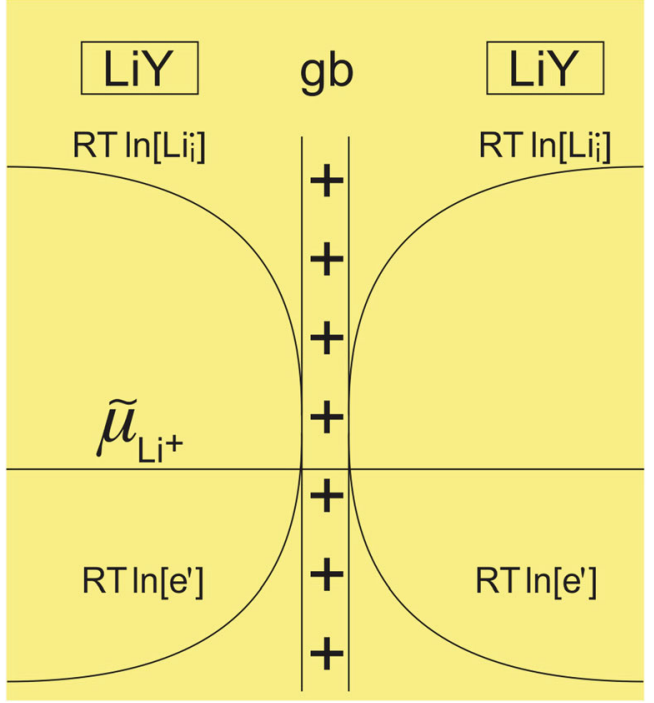

Fig. 1 Depletion zones at grain boundaries (here for the case of positive core charge). The figure is relevant for electrode/electrolyte contacts, too. Note that such effects change the electronic conductivity as well. A favorable excess charge may also lead to accumulation layers and enhanced conductivities

"heterogeneous dopant", room temperature values of almost $10^{-3} \mathrm{~S} / \mathrm{cm}$ could be achieved $[38,39]$.

A specific problem not faced by liquids is the question of isotropy and dimensionality of the conduction pathways. Onedimensional conduction pathways are typically not favorable for long-range conduction as they are easily blocked by disorder (e.g. in the hollandites [40]). Two-dimensional pathways do not face this problem but still require a favorable microstructure for percolative reasons.

A great advantage of solid electrolytes is the fact that one usually encounters single ion motion. In a binary, for example, it is required that only either the cation or the anion is mobile but the counter ion is immobile, otherwise the material would flow. In liquid electrolytes typically cations and anions are mobile. Only space charge controlled liquid electrolytes enable the possibility of transport numbers approaching unity (soggy-sand electrolytes, ion exchange membranes) [41]. Since in a Li-battery the electrodes are usually reversible for $\mathrm{Li}^{+}$but not for the other ions, concentration gradients build up during operation. The precise treatment is particularly delicate if association effects play a role [42]. This does not only lead to losses owing to concentration polarization but may even lead to salt precipitation under high drain (Fig. 2).

\section{(ii) Electronic Conductivity}

A very characteristic issue of solids is the occurrence of electronic conduction. Even though preferentially very small, it is never zero in solid electrolytes. Note that even very small electronic conductivities can lead to perceptible self-discharge, in particular if the battery is not under constant use. 


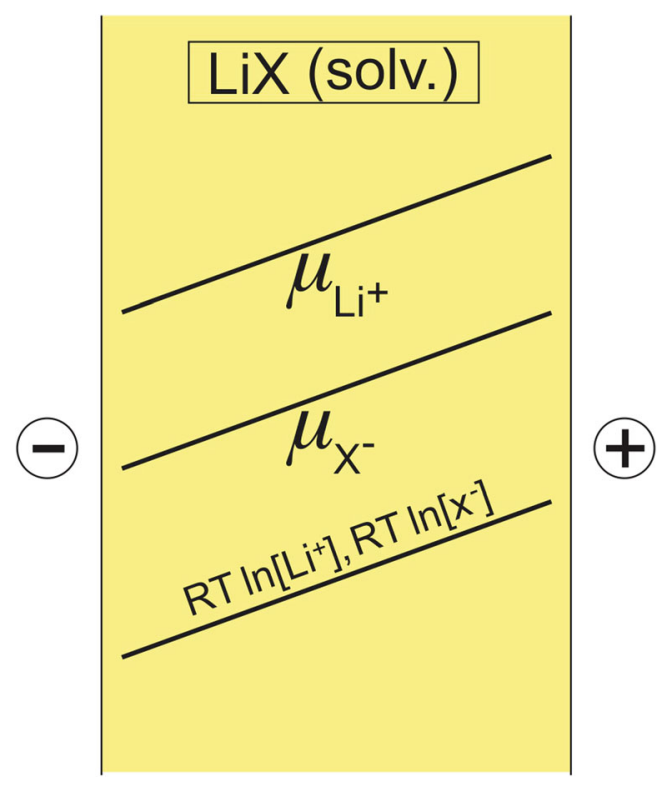

Fig. 2 Concentration polarization of a Li-salt solution. At high values of salt concentration (i.e. under high drain) salt precipitation may occur. Very close to the interface space charge zones occur

Even though free electronic motion does not occur in liquid electrolytes, they may show self-discharge owing to indirect electronic conduction via redox-active ions.

\section{(iii) Transfer Resistances}

In addition to transfer resistances owing to internal boundaries, it is the electrode/electrolyte transfer resistance that is crucial [7]. At a first glance solid/solid contacts offer the advantage that it is not necessary for the ion to strip off a solvation shell when going from the electrolyte into the electrode phase, but comparable relaxation phenomena complicate the situation in solids, too. In addition to the usual electrochemical transfer resistance, serious resistive contributions can stem from carrier depletion zones at the electrolyte/electrode contact [37] analogously to Fig. 1. Particularly difficult is the transfer if the solid/ solid contact is not ideal as it is usually the case (cf Fig. 3). A detailed simulation of such effects was given in refs. [43, 44] (cf. also (iii)). Many authors aim at hybrid electrolytes, typically liquid electrolyte cells in which solids are used as protection layers with respect to electrode phases. Note that this involves additional, typically very significant transfer resistances.

\subsection{Chemical stability}

It is an often met prejudice that solids are thermodynamically more stable with respect to electrodes of very high or very low $\mathrm{Li}$ potential. In fact, almost all relevant $\mathrm{Li}$-electrolytes known so far are thermodynamically unstable against metallic lithium. Exceptions are the binaries which are either poorly conducting (LiI) or highly reactive $\left(\mathrm{Li}_{3} \mathrm{~N}\right) \cdot \mathrm{Li}_{2} \mathrm{ZrO}_{3}$ seems marginally stable

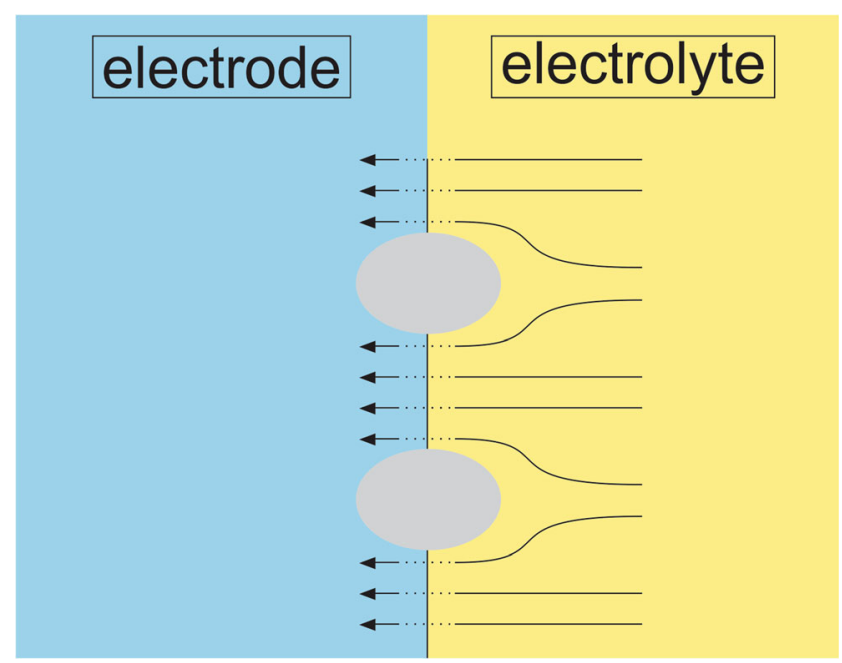

Fig. 3 Current path lines showing constriction and hindered phase transfer. Such effects become much more severe in a nano-particulate network

but is very brittle (see Section 3.2.(ii)) [45]. Most of these electrolytes, in particular the sulfides, are thermodynamically unstable against the high voltage cathodes as well. Binaries such as LiI, $\mathrm{Li}_{3} \mathrm{P}, \mathrm{Li}_{2} \mathrm{~S}, \mathrm{Li}_{3} \mathrm{~N}$ are stable against contact with the non-metallic component, but naturally have a very low thermodynamic window. In Part II, calculated thermodynamic windows of various $\mathrm{Li}$ compounds will be shown - here it suffices to state that, as Fig. 4(a), (b) indicates for the example of LiI, the often used $\mathrm{HOMO} / \mathrm{LUMO}$ distance largely overestimates the stability windows since it ignores chemical rearrangements and reactions during the decomposition process. In LiI the band gap approximately reflects the local free energy of forming neutral $\mathrm{Li}$ and I states within LiI (Fig. 4(b)), while the actual decomposition involves formation of the metallic Li phase and gaseous $\mathrm{I}_{2}$ substantially lowering the reaction free enthalpy (Fig. 4(a)). This refers to the "intrinsic" stability. The true, "extrinsic" stability is additionally lowered by chemical reactions with actually present electrode phases.

Obviously, the use of solid electrolytes also has to rely on passivation layers as for liquid electrolytes $(\mathrm{SEI}=$ Solid Electrolyte Interface). Such SEI layers must have sufficiently high ionic conductivity so as to enable access of ions to the electrode, but low enough electronic conductivity so as not to grow to macroscopic dimensions. The thermodynamic effect of the SEI in making compatible the high (low) value of the chemical potential of $\mathrm{Li}$ in the anode (cathode) with the much lower (higher) value in the electrolyte is also obvious from Fig. 4(c) showing the situation within a thin LiI layer formed at the contact of two neighboring phases of very high (Li) and very low chemical potential of $\mathrm{Li}\left(\mathrm{I}_{2}\right)$. This point will be taken up in Part II again. Substantial advantages in energy density are only realizable if the choice of the SE allows one to use electrodes of higher (Li-metal) or lower chemical potential (5 $\mathrm{V}$ materials) than is possible with liquid electrolytes. Whether this is kinetically achievable relies on the possibility 

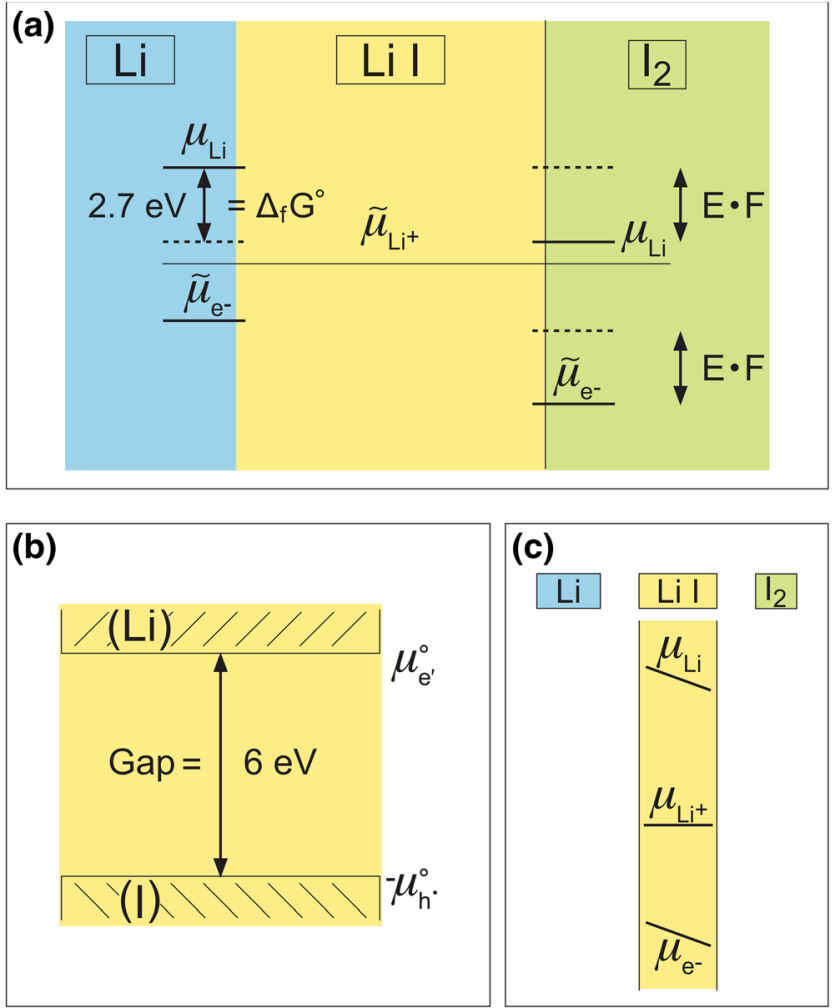

Fig. 4 (a) shows the thermodynamic window of LiI ( $\mu$ : chemical potential, $\tilde{\mu}$ : electrochemical potential); (b) shows that this window is largely overestimated by the band gap; (c) gives the chemical potentials of $\mathrm{Li}, \mathrm{Li}^{+}$and $\mathrm{e}^{-}$for a $\mathrm{LiI}$ film thin enough as to allow for electronic equilibration. (In the space charge zones close to the contacts the $\mu$-values for ions and electrons deviate from the course shown.) Fig. 4(c) is also meaningful in indicating the stabilization effect achieved by ionically conducting passivation layers (SEI)

of forming well-suited passivation layers, a kinetic point that is hard to predict and has to be tested in detail (see also Fig. 4(c), and Fig. 7(b) below).

A natural advantage of solids seems that they suppress dendrite formation. Many studies, however, have shown that grain boundaries also allow for dendrite propagation [46]. Use of thick Li-films is anyway difficult owing to the geometric changes involved on charging and discharging; it seems favorable if only a small fraction of the film is cycled. At any rate, dendrite formation is less probable for homogeneous contacts and absence of higher-dimensional defects in the electrolyte.

An uncontestable advantage of many solid electrolytes is their stability with respect to ambient conditions. Many of them - especially the oxides, but less so the sulfides - do not react or only sluggishly with oxygen or water, while typical liquid electrolytes are flammable (ionic liquids).

\subsection{Mechanical stability}

Most serious issues in this context are connected with mechanical aspects. The same reasons that on the one hand provide many pros such as single ion motion, formability, thickness reduction, shape stability and significant increases of volumetric stack energy density, are responsible for significant problems on the other hand. Crack formation on mechanical stress is a crucial point that can, depending on the crack propagation kinetics, lead to catastrophic failure [47] (in fact, crack formation in $\beta$-alumina was the reason that $\mathrm{ABB}$ stopped production of the $\mathrm{Na}-\mathrm{S}$ cells for electro-traction).

Poor contact to other solid phases is the second severe point. Within the material this is responsible for grain boundary resistances already mentioned; at the electrode/electrolyte interface it is the unfavorable contact behavior and the low mechanical stability and flexibility that not only cause high transfer resistances but eventually cell failure. In particular in high performance batteries where electrodes are composed of a multi-particulate network for which contact to the electrolyte is required on the nano-scale, it is hard to imagine how a sufficient wetting is to be realized at least with brittle ceramics. Recent publications [48, 49] promise overcoming of such problems by using assisting interlayers and a well-suited pore structure. Soft polymers or glassy phases are certainly much better candidates from the mere mechanical viewpoint. Even if such a good contact is established, e.g., via glassy electrolytes, the contacts need to be flexible not only in the course of further processing but also upon the volume changes during performance.

\subsection{Thermal properties}

Insufficient matching of thermal expansion coefficients causes mechanical problems if temperature variations are involved in the fabrication process [47]. Otherwise the typically higher thermal conductivity of solids - when compared to liquids is an advantage as hot-spot effects are mitigated.

In addition, the higher thermal stability of solids is an advantage that may eventually enable overcoming the most severe drawbacks by allowing performance at elevated temperature.

\section{Lithium superionic conductors}

\subsection{General overview}

While $\mathrm{Li}$ ion conduction in solids has been a ubiquitous topic in solid-state ionics since the early days of the field, Li solid electrolytes had not been considered serious competitors to liquid electrolytes in practical electrochemical devices until very recently. Out of the three strategies to realize highly conducting solid electrolytes, viz. enhancing the carrier concentration by homogeneous (i) or heterogeneous doping (ii) [37-39] and synthesizing superionic compounds (iii) [33], it is the third that made the running. 
Recent developments in novel glassy Li ion conductors including various oxynitrides, prominently represented by LiPON, and oxysulfides are manifold, some of them characterized by high conductivities [34]. Yet, apart from LiPON (which however has not a very high conductivity), systematic investigations regarding long-time stability are lacking. The same holds true for the partly very high $\mathrm{Li}$ conductivities $\left(10^{-3}-10^{-2} \mathrm{~S} / \mathrm{cm}\right)$ achieved in glass-ceramics in the $\mathrm{Li}_{2} \mathrm{~S}-\mathrm{P}_{2} \mathrm{~S}_{5}$ system [50].

For this reason, and also for the sake of conciseness, we will not consider amorphous SE in greater detail. Likewise, equally highly conducting rotator phases (typically $\mathrm{Li}_{2} \mathrm{SO}_{4}$ ) will not be treated here, as they are not of direct relevance for batteries.

As crystalline ion conductors, on the other hand, offer the advantage of high structural definition enabling well-defined ionic transport pathways in solids with mobile ionic sublattices embedded in a rigid anionic backbone, they are the best candidates for the study of single ion conduction. Examples are copper and silver superionic conductors prominently represented by $\mathrm{Rb}_{4} \mathrm{Cu}_{16} \mathrm{I}_{7} \mathrm{Cl}_{13}$ and $\mathrm{RbAg}_{4} \mathrm{I}_{5}$, with $\mathrm{Cu}$ and $\mathrm{Ag}$ conductivities higher than in any copper or silver-based vitreous system.

In spite of such examples, $\mathrm{Li}$ conductivities in crystalline solids have fallen short of their $\mathrm{Cu}$ and $\mathrm{Ag}$ analogues for decades. One of the earliest examples of crystalline oxide $\mathrm{Li}$ ion conductors was described in the system $\mathrm{Li}_{16-2 x} D_{x}\left(T \mathrm{O}_{4}\right)_{4}$, where $D$ is a divalent cation such as $\mathrm{Mg}^{2+}$ or $\mathrm{Zn}^{2+}, \mathrm{T}$ is a tetravalent cation $\left(\mathrm{Si}^{4+}\right.$ or $\left.\mathrm{Ge}^{4+}\right)$ and $0<x<4$. The prototype $\mathrm{Li}_{14} \mathrm{ZnGe}_{4} \mathrm{O}_{16}$, reported by Hong in 1978 [51] and known as LISICON (LIthium SuperIonic CONductor), features a rigid rigid three-dimensional (3D) structure with orthorhombic symmetry (space group Pnma) related to $\gamma-\mathrm{Li}_{3} \mathrm{PO}_{4}$. The anionic framework with composition $\mathrm{Li}_{11} \mathrm{Zn}\left(\mathrm{GeO}_{4}\right)_{4}$ hosts the three remaining Li ions on two interstitial sites with $55 \%$ (4c) and $16 \%$ (4a) occupancy, forming a highly mobile sublattice that shows only weak bonding with the rigid anionic framework. Like in $\beta$-alumina, the ionic transport in LISICON is largely two-dimensional (2D). Reported conductivities vary widely between $10^{-6}$ at room temperature [52] and $1.3 \times 10^{-1} \mathrm{~S} / \mathrm{cm}$ at $300{ }^{\circ} \mathrm{C}$ [51]. An obvious drawback is LISICON's high reactivity towards metallic $\mathrm{Li}$ as well as the fact that it readily reacts with atmospheric $\mathrm{CO}_{2}$, leading to a decrease in conductivity over time.

Crystalline oxide-based $\mathrm{Li}$ ion conductors with relevant room temperature conductivities approaching $10^{-3} \mathrm{~S} / \mathrm{cm}$ have been identified in three materials systems: the LLTO, NASICON-derived and garnet-type families of compounds. To date, one of the best oxide Li ion conductors is the solid solution lithium lanthanum titanate (LLTO) $\mathrm{Li}_{3 x} \mathrm{La}_{(2 / 3)-x} \square_{(1 / 3)-2 x} \mathrm{TiO}_{3}(0.06<x<0.16$, highest Li conductivity of $1.4 \times 10^{-3} \mathrm{~S} / \mathrm{cm}$ observed for $\mathrm{x}=0.11$ ) [53], which is derived from the parent $\mathrm{ABO}_{3}$-type perovskite $\mathrm{La}_{(2 / 3)} \square_{(1 / 3)} \mathrm{TiO}_{3}$ [54]. Substitution of La by Li and the presence of a large A-site vacancy concentration in the tetragonal perovskite structure allows for facile diffusion of Li through vacant A-site cages, separated by oxygen bottlenecks. The static La disorder and slight tilting of the $\mathrm{TiO}_{6}$ octahedra, along with the effect of temperature on the aperture size of the square-planar oxygen windows lead to a crossover from $2 \mathrm{D}$ motion at $T<200 \mathrm{~K}$ to $3 \mathrm{D}$ diffusion at $T>200 \mathrm{~K}[55,56]$. Although LLTO has high Li conductivity and excellent thermal and moisture stability, there are two severe drawbacks that impair its use in practical thin film batteries with Li metal as anode: First, the high grain boundary resistance leading to much lower conductivities in polycrystalline ceramic samples as compared to single crystals, and second, the easily reducible $\mathrm{Ti}^{4+}$ ions may lead to interfacial electronic conductivity and even internal shortcuts.

Li conductors with NASICON-type structure are composed of a 3D anionic network with rhombohedral symmetry composed of corner-sharing $\mathrm{AO}_{6}$ octahedra and $\mathrm{PO}_{4}$ tetrahedra, similar to that in $\mathrm{Na}_{3} \mathrm{Zr}_{2} \mathrm{PSi}_{2} \mathrm{O}_{12}$. Substituting Ti in lithium titanium phosphate $\mathrm{LiTi}_{2}\left(\mathrm{PO}_{4}\right)_{3}$ by trivalent cations with slightly smaller $\left(\mathrm{Al}^{3+}\right)$ or larger radii such as $\mathrm{Ga}^{3+}, \mathrm{In}^{3+}, \mathrm{Sc}^{3+}$, $\mathrm{Y}^{3+}$, and $\mathrm{La}^{3+}$, yields substitutional variants with bulk conductivities as high as $3 \times 10^{-3} \mathrm{~S} / \mathrm{cm}$ at room temperature for the $x=0.3$ member $\mathrm{Li}_{1.3} \mathrm{Al}_{0.3} \mathrm{Ti}_{1.7}\left(\mathrm{PO}_{4}\right)_{3}$ (LATP) [57].

As for LLTO ceramics, a major drawback for Li conductors with NASICON-type structure is the fact that $\mathrm{Ti}^{4+}$ is easily reduced to $\mathrm{Ti}^{3+}$ in contact with $\mathrm{Li}$, leading to phases with significant electronic conductivity.

More recently, $\mathrm{Li}$ ion conductors with garnet-type structure derived from the prototype $\mathrm{Li}_{5} \mathrm{La}_{3} \mathrm{M}_{2} \mathrm{O}_{12}(M=\mathrm{Ta}, \mathrm{Nb})$ [58] have been discovered, featuring a broad substitutional range and Li conductivities up to $4.0 \times 10^{-5} \mathrm{~S} / \mathrm{cm}$ at room temperature for the Ba-doped variant $\mathrm{Li}_{6} \mathrm{SrLa}_{2} \mathrm{Ta}_{2} \mathrm{O}_{12}$ [59]. The highest $\mathrm{Li}$ conductivities amongst the garnet-type Li ion conductors so far were found in the highly Li-stuffed system $\mathrm{Li}_{7} \mathrm{La}_{3} \mathrm{Zr}_{2} \mathrm{O}_{12}$ (LLZO) with conductivities reaching $1 \times 10^{-3} \mathrm{~S} / \mathrm{cm}$ upon partial replacement of $\mathrm{Zr}$ by $\mathrm{Te}, \mathrm{Ta}$ or $\mathrm{Nb}$ [60].

The negligible electronic conductivity, high chemical stability and large electrochemical window ( $>6 \mathrm{~V}$ vs Li; kinetic durability/inertness against molten Li) are clearly assets that are currently hard to achieve in other Li SE systems.

It has been realized early on that larger and more polarizable anions tend to enhance the mobility of the cationic species substantially. Replacing oxygen in oxide Li ion conductors by sulfur has led to the discovery of sulfide-based glassy ceramics with Li conductivities in the range of $10^{-4}$ to $10^{-3} \mathrm{~S} / \mathrm{cm}$ at room temperature, for example in solid solution members of the systems $\mathrm{Li}_{2} \mathrm{~S}-\mathrm{SiS}{ }_{2}$-LiI [61] or $\mathrm{Li}_{2} \mathrm{~S}-\mathrm{SiS}_{2}-\mathrm{Li}_{3} \mathrm{PO}_{4}$ [62]. This "design" principle - the replacement of oxygen by sulfur in tetrahedral anionic sublattices featuring strongly covalent bonding, combined with aliovalent cation substitution to dope the system either with $\mathrm{Li}$ vacancies or $\mathrm{Li}$ interstitials - was used by Kanno and co-workers to prepare the first crystalline sulfidebased $\mathrm{Li}$ ion conductor with conductivities exceeding $1 \times 10^{-3} \mathrm{~S} /$ $\mathrm{cm}$ in 2001 [63]. The solid solution $\mathrm{Li}_{4-x} \mathrm{Ge}_{1-x} \mathrm{P}_{x} \mathrm{~S}_{4}$ was 
obtained by aliovalent substitution $\mathrm{Ge}^{4+}+\mathrm{Li}^{+} \leftrightarrow \mathrm{P}^{5+}$ in the solid solution $\mathrm{Li}_{2} \mathrm{~S}-\mathrm{GeS}_{2}-\mathrm{P}_{2} \mathrm{~S}_{5}$. The end members $\mathrm{Li}_{4} \mathrm{GeS}_{4}$ and $\mathrm{Li}_{3} \mathrm{PS}_{4}$ are isotypic with orthorhombic $\gamma-\mathrm{Li}_{3} \mathrm{PO}_{4}$, while a monoclinic superstructure was found for solid solution members $\mathrm{Li}_{4-x} \mathrm{Ge}_{1-x} \mathrm{P}_{x} \mathrm{~S}_{4}$ with $x>0.6$, corresponding to different types of cation ordering [63]. Overall, the 3D framework structure of thio-LISICON is very closely related to that of its oxide counterpart LISICON. As in the latter, the best performing thioLISICON solid solution member $\left(\sigma=2.2 \times 10^{-3} \mathrm{~S} / \mathrm{cm}\right.$ at $\left.25^{\circ} \mathrm{C}\right)$ with the composition $\mathrm{Li}_{3.25} \mathrm{Ge}_{0.25} \mathrm{P}_{0.75} \mathrm{~S}_{4}$ is a vacancy-doped system; aliovalent cation substitution of $\mathrm{Ge}^{4+}$ with trivalent cations such as $\mathrm{Al}^{3+}$ leads to interstitial ion-doped systems such as $\mathrm{Li}_{4+x} \mathrm{Si}_{1-x} \mathrm{Al}_{x} \mathrm{~S}_{4}$ and $\mathrm{Li}_{4+x} \mathrm{Ge}_{1-x} \mathrm{Ga}_{x} \mathrm{~S}_{4}$ with slighly lower conductivities. The solid solution member $x=0.6$ in $\mathrm{Li}_{4-x} \mathrm{Si}_{1-x} \mathrm{P}_{x} \mathrm{~S}_{4}$ shows an ionic conductivity of $6.4 \times 10^{-4} \mathrm{~S} / \mathrm{cm}$ [64]. Further desirable properties of the thio-LISICONS are (i) negligible electronic conductivity, (ii) thermal stability up to $500{ }^{\circ} \mathrm{C}$ (without phase transitions), (iii) high apparent, i.e. kinetic chemical stability (no reaction with Li metal) and (iv) a large nominal electrochemical stability window between 0 and $5 \mathrm{~V}$ vs $\mathrm{Li}^{2} \mathrm{Li}^{+}$.

More recently, Li argyrodites have been identified as potentially fast chalcogenide-based $\mathrm{Li}$ ion conductors. Like their $\mathrm{Cu}$ and $\mathrm{Ag}$ analogues, $\mathrm{Li}$ argyrodites crystallize in tetrahedral close-packed structures of the anions with topologies similar to those of the cubic Laves phase $\mathrm{MgCu}_{2}$ with $\mathrm{Li}$ randomly distributed across tetrahedral interstitials in the cubic high temperature modification (space group $\bar{F} \overline{4} 3 m$ ). Li argyrodites are generally represented by the formulas $\mathrm{Li}_{7} \mathrm{PCh}_{6}$ or $\mathrm{Li}_{7-x} \mathrm{BCh}_{6-x} \mathrm{X}_{x}(\mathrm{~B}=\mathrm{P}$, As; $\mathrm{Ch}=\mathrm{S}, \mathrm{Se} ; \mathrm{X}=\mathrm{Cl}, \mathrm{Br}$, I; $0<x \leq 1$ ), which indicates the large scope of substitutional patterns by both aliovalent and isovalent substitutions on both the cation and anion sublattices $[65,66]$. Li argyrodites have been reported to show $\mathrm{Li}$ conductivities in the range of $10^{-3}-10^{-2} \mathrm{~S} / \mathrm{cm}$ by Deiseroth and co-workers $[67,68]$. Together with the observed excellent electrochemical inertness between 0 and $7 \mathrm{~V}$ vs Li/ $/ \mathrm{Li}^{+}$as well as the low electronic conductivity of $<10^{-10} \mathrm{~S} / \mathrm{cm}$ [69], the argyrodites show performance parameters roughly en par with those of the thioLISICONs.

\subsection{LGPS solid electrolytes}

While the thio-LISICONs and $\mathrm{Li}$ argyrodites still lag behind in terms of the conductivities seen in liquid electrolytes, the recent discovery of a new generation of thio-LISICONs - the LGPS family of compounds - has closed this gap. The tetragonal compound $\mathrm{Li}_{10} \mathrm{GeP}_{2} \mathrm{~S}_{12}$ (LGPS) with $P 4_{2} / n m c$ symmetry was found by Kanno et al. to show $\mathrm{Li}$ ion conductivities as high as $1.2 \times 10^{-2} \mathrm{~S} / \mathrm{cm}$ at room temperature, which is one order of magnitude larger than those found in thio-LISICONS and puts the Li ion conductivity of LGPS en par with those achieved in common liquid electrolytes [2].
It is obvious that this disruptive increase in ionic conductivity found in a crystalline SE will breathe new life into the community's efforts to reduce all-solid-state Li batteries to practice. We will therefore take a closer look at this promising new SE and discuss pertinent properties of LGPS and its congeners with a view towards their use as practical SEs in allsolid-state $\mathrm{Li}$ batteries. Where applicable, we will refer to the key issues of Li solid electrolytes - electrochemical properties, chemical stability, mechanical stability and thermal properties - as discussed in the first part of this review.

(i) Structural and electrochemical properties

Structure, diffusion mechanism, and ionic conductivity In LGPS, the 3D lattice is composed of one-dimensional (1D) chains of edge-sharing $(\mathrm{Ge}, \mathrm{P}) \mathrm{S}_{4}$ tetrahedra and $\mathrm{LiS}_{6}$ octahedra running along the [001]-direction, which are surrounded by mobile $\mathrm{Li}$ ions; $\mathrm{PS}_{4}$ tetrahedra bridge those chains along the [110] direction (Fig. 5) [2]. While in LGPS the $2 b$ sites are occupied by $\mathrm{P}$ only, there is mixed $(\mathrm{Ge}, \mathrm{P})$ occupancy of the (larger) $4 d$ site, determined by the stoichiometry of the solid solution. For example, in the Ge compound the occupancy $\left(\mathrm{Ge}_{x} \mathrm{P}_{1-x}\right)$ of the $4 d$ site can be varied in the range of $0.5 \leq x(\mathrm{Ge}) \leq 0.75$, corresponding to $\mathrm{Li}_{7} \mathrm{GePS}_{8}$ and $\mathrm{Li}_{10} \mathrm{GeP}_{2} \mathrm{~S}_{12}$ as the end members of the solid solution [3].

The aliovalent substitution $\mathrm{Ge}^{4+}+\mathrm{Li}^{+} \leftrightarrow \mathrm{P}^{5+}$ introduces vacant $\mathrm{Li}$ sites which enable fast $\mathrm{Li}$ diffusion in the channels running along the $c$ direction. This predominant diffusion pathway has given rise to the notion that Li diffusion in LPGS-type materials is inherently one-dimensional. In general, low-dimensional or even single-file diffusion in ionic conductors is problematic, as it can easily lead to blocking effects in non-ideal samples, as discussed in Part I. However, the notion of 1D conductivity in LGPS primarily arose from the fact that in early powder diffraction studies only three Li positions had been identified, of which one was assumed to be essentially immobile (Li2). As suggested by calculations by Adams and Rao, a fourth Li position (Li4) was later identified experimentally by single-crystal analysis [70]. Li4 connects the Li3 - [Li1 - Li1] - Li3 diffusion channels along $c$ and opens up the possibility for Li diffusion also in the $a-b$ plane. Indeed, Janek, Zeier and co-workers [71] confirmed the significant contribution of the in-plane Li diffusion (along $\mathrm{Li} 3-[\mathrm{Li} 2-\mathrm{Li} 2]-\mathrm{Li} 3$ and $\mathrm{Li} 4-[\mathrm{Li} 1-\mathrm{Li} 1]-\mathrm{Li} 4)$ pathways by neutron powder diffraction combined with a maximum entropy analysis. Hence, they demonstrated that already at room temperature a quasi $3 \mathrm{D}$ diffusion mechanism is operative in LGPS, with the 3D character of Li diffusion further increasing at higher $\mathrm{T}[71,72]$ (Fig. 6).

In spite of the similar chemical composition and structure of the thio-LISICONs and LGPS-type compounds, the Li conductivity in the latter is one order of magnitude higher. It is 


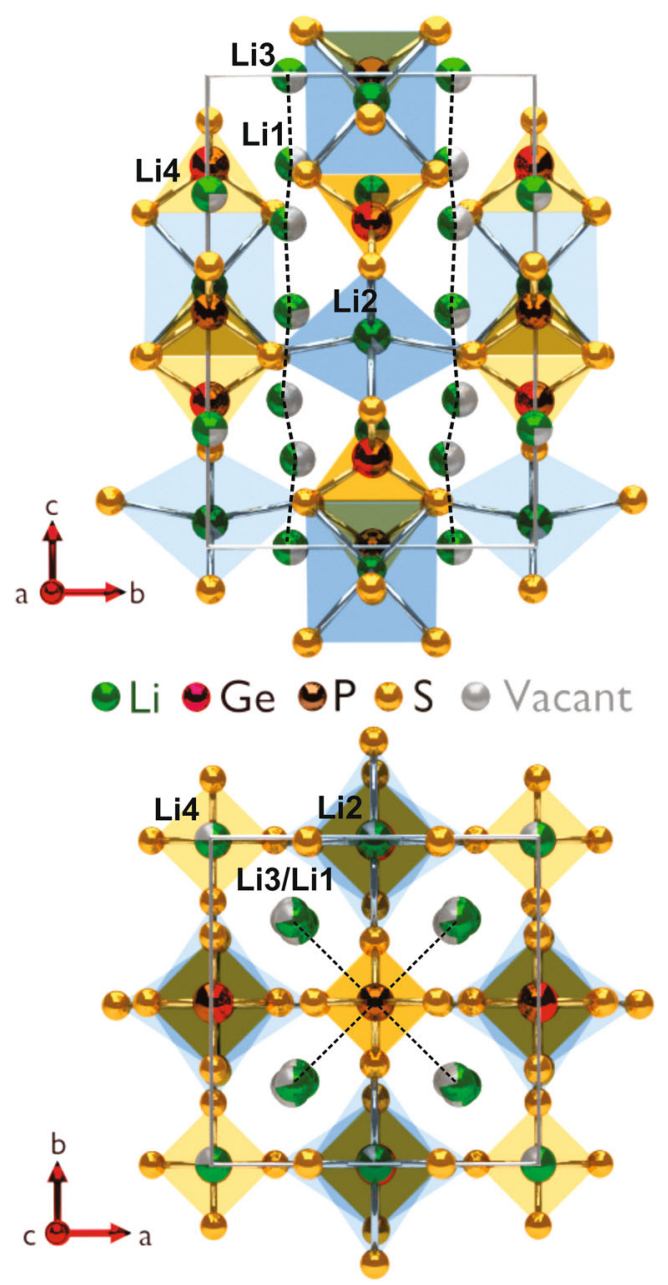

Fig. 5 Crystal structure of LGPS viewed along [100] (top) and along [001] (bottom). $\mathrm{PS}_{4}$ and $(\mathrm{Ge}, \mathrm{P}) \mathrm{S}_{4}$ tetrahedra are drawn in yellow, $\mathrm{LiS}_{6}$ octahedra in blue. Li diffusion pathways are indicated by dotted lines

instructive to look at this striking difference in more detail: In line with recent calculations by Wang et al. [73], the topology of the sulfide sublattice and the resulting Li migration paths and their energy landscape are important descriptors for the observed Li conductivities. Essentially all fast Li ion conductors in the sulfide glasses, glass-ceramics and crystalline sulfide systems are characterized by predominantly tetrahedral coordination of $\mathrm{Li}$ and the anionic framework constituents such as $\mathrm{P}, \mathrm{Ge}, \mathrm{Si}$ etc. However, while the orthorhombic ternaries such as $\gamma-\mathrm{Li}_{3} \mathrm{PS}_{4}$ and $\mathrm{Li}_{4} \mathrm{GeS}_{4}$, from which the thioLISICON structure derives, have a have a distorted $h c p$ sulfur sublattice, the one in LGPS closely matches a $b c c$ sulfur sublattice. In contrast to $h c p$ and $f c c$ sublattices where long range $\mathrm{Li}$ diffusion includes octahedral $(\mathrm{O})$ sites, leading to higher energy barriers, Li migration in the bcc-type lattice predominantly occurs between tetrahedral $(\mathrm{T})$ sites with minimal calculated and experimentally observed activation energies for the T-T trajectories of $0.15 \mathrm{eV}$ [73] and 0.22 $0.24 \mathrm{eV}$, respectively $[2,3]$. The $b c c$ sublattice is also found in the glass-ceramic conductor $\mathrm{Li}_{7} \mathrm{P}_{3} \mathrm{~S}_{11}\left(\mathrm{Li}_{2} \mathrm{~S}-\mathrm{P}_{2} \mathrm{~S}_{5}\right.$ system) which likewise shows extremely high ionic conductivities of $1.7 \times 10^{-2} \mathrm{~S} / \mathrm{cm}$ and a very low activation energy of $0.176 \mathrm{eV}$ [50]. It is this difference in the activation energies for the T-T vs T-O-T paths that can account for changes in the Li conductivity at RT by three orders of magnitude. This does not only emphasize the important role of the framework structure and topology in identifying fast ionic conductors, but also demonstrates a powerful "design" principle which we have at our disposal for crystalline, rather than amorphous ion conductors.

Composition and phase stability Like in the thio-LISICON system, LGPS-type ionic conductors span a fairly broad range of compositions and allow for iso- and aliovalent substitutions. These have been realized for example in the systems $\mathrm{Li}_{2} \mathrm{~S}-\mathrm{SiS}_{2}-\mathrm{P}_{2} \mathrm{~S}_{5}, \mathrm{Li}_{2} \mathrm{~S}-\mathrm{SnS}_{2}-\mathrm{P}_{2} \mathrm{~S}_{5}, \mathrm{Li}_{2} \mathrm{~S}-\mathrm{Al}_{2} \mathrm{~S}_{3}-\mathrm{P}_{2} \mathrm{~S}_{5}$ and mixtures thereof [74], or the anion- and mixed anion-cation doped systems $\mathrm{Li}_{2} \mathrm{~S}-\mathrm{GeSe}_{2}-\mathrm{P}_{2} \mathrm{~S}_{5}$ or $\mathrm{Li}_{2} \mathrm{~S}-$ (1-z) $\mathrm{GeS}_{2}-\mathrm{z} \mathrm{SnSe}_{2}-\mathrm{P}_{2} \mathrm{~S}_{5}$ [75]. In most cases, however, admixtures of the orthorhombic thio-LISICON modification were present or exclusively formed as in the case of $\mathrm{Li}_{11} \mathrm{AlP}_{2} \mathrm{~S}_{12}$, reflected by significantly lower conductivities [76]. Theoretical calculations by Ceder and co-workers suggest - and this is not surprising in view of the large carrier concentrations -that both iso- and aliovalent cation substitutions in the LGPS-type compounds do not lead to drastic changes in both diffusivity and activation energy $\left(E_{\mathrm{A}}\left(\mathrm{Li}_{11} \mathrm{AlP}_{2} \mathrm{~S}_{12}\right)=0.18 \pm 0.06 \mathrm{eV}\right.$ vs $E_{\mathrm{A}}$ $\left(\mathrm{Li}_{10} \mathrm{SiP}_{2} \mathrm{~S}_{12}\right)=0.20 \pm 0.03 \mathrm{eV}$ v s $E_{\mathrm{A}}$ $\left(\mathrm{Li}_{10} \mathrm{GeP}_{2} \mathrm{~S}_{12}\right)=0.21 \pm 0.04 \mathrm{eV}$ vs $E_{\mathrm{A}}$ $\left.\left(\mathrm{Li}_{10} \mathrm{SnP}_{2} \mathrm{~S}_{12}\right)=0.24 \pm 0.03 \mathrm{eV}\right)$ [77]. Furthermore, the calculations suggest that anion substitution will have a slightly more pronounced effect than cation substitution as the former influences the channel size more strongly, which is an important parameter for Li ion diffusivity. The calculations indicate that while in the hypothetical $\mathrm{Li}_{10} \mathrm{GeP}_{2} \mathrm{O}_{12}$ the diffusivity is expected to be significantly lower with activation energies around $0.36 \mathrm{eV}$, the selenium analogue $\mathrm{Li}_{10} \mathrm{GeP}_{2} \mathrm{Se}_{12}$ is expected to show only slightly improved conductivities with activation energies being the same as those in LGPS within the error bar [77]. These findings suggest that both the carrier concentration and channel size in LGPS is close to their optimal values with little room for significant improvements in the $\mathrm{Li}$ conductivity by compositional variations.

In fact, the tetragonal Si- and Sn-homologues of LGPS have recently been synthesized and their conductivities determined by impedance spectroscopy. While the conductivity 




(c)
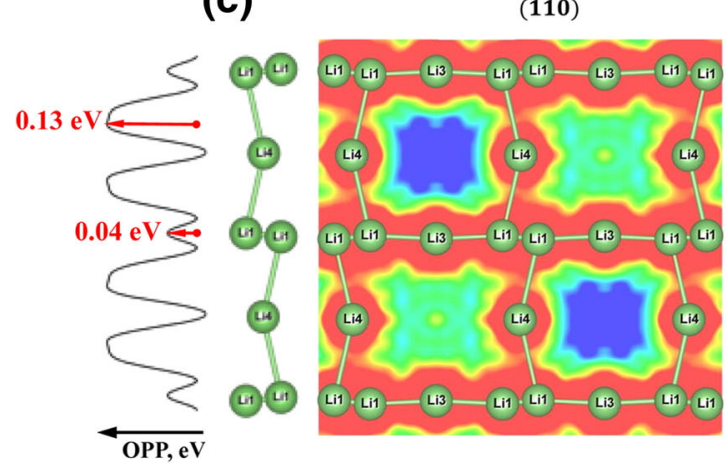

Fig. 6 (a) Nuclear density maps showing the 3D Li distribution for different sections of the unit cell as obtained by powder neutron diffraction of LGPS. Selected slices with corresponding Li one-particlepotential (OPP) as recalculated from negative nuclear densities along the (b)

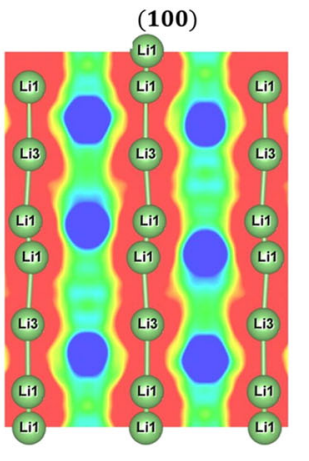

(d)

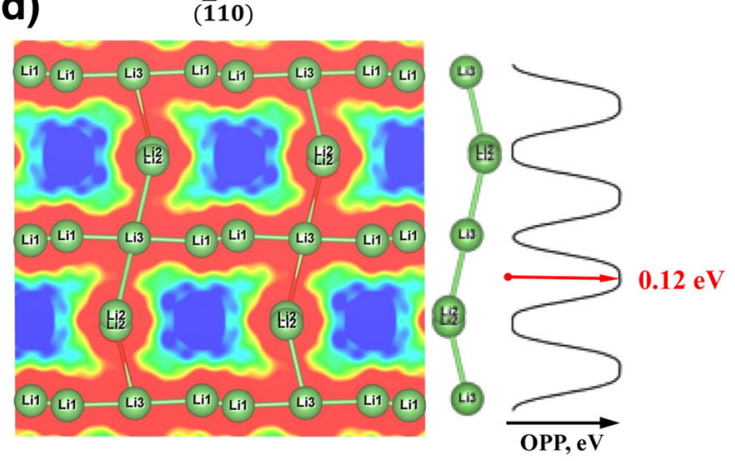

1D Li pathways along Li3 - [Li1 - Li1] - Li3 (b) Li4 - [Li1 - Li1] - Li4 (c) and $\mathrm{Li3}-[\mathrm{Li} 2-\mathrm{Li} 2]-\mathrm{Li} 3$ (d) which are characterized by different energy barriers. Adapted from Ref. [71] with permission

spectroscopy, but also the grain boundary contributions and interfacial characteristics when the SE is brought in contact with electrodes.

Electronic conductivity As discussed in Part I of this review, a good SE must have vanishingly low electronic conductivity in order to avoid self-discharge and, hence, to extract the maximum energy through the external circuit, as well as to prevent the solid components from changing chemically during operation. The electronic contribution to the overall electrical conductivity in LSnPS was studied by DC polarization measurements using a symmetric configuration with ion blocking $\mathrm{Au}$ electrodes $\mathrm{Au}|\mathrm{LSnPS}| \mathrm{Au}$. The polarization measurements reveal a vanishingly small electronic conductivity with an upper limit of the transference number $t_{\mathrm{EON}}$ of $1 \mathrm{ppm}$ [3]. Negligible electronic conductivity was previously also found for the thioLISICON [63] $\mathrm{Li}_{4-x} \mathrm{Ge}_{1-x} \mathrm{P}_{x} \mathrm{~S}_{4}$ and seems to hold for LGPStype materials in general.

\section{(ii) (Electro)chemical stability}

One of the most prominent perceived advantages of solid electrolytes is their expected higher chemical and electrochemical stability as compared to liquid electrolytes [78].

affect the bulk conductivity as measured by impedance 
LGPS-type materials - like thio-LISICONs - were reported to exhibit an electrochemical stability window (ESW) as large as 0 to $>5 \mathrm{~V}$ vs Li/ $/ \mathrm{Li}^{+}$, which is highly desirable for cell designs using Li metal as anode and high voltage cathodes such as $\mathrm{Li}_{x} \mathrm{CoO}_{2}, \mathrm{Li}\left(\mathrm{Ni}_{1 / 3} \mathrm{Mn}_{1 / 3} \mathrm{Co}_{1 / 3}\right) \mathrm{O}_{2}$, or $\mathrm{LiNiPO}_{4}$. However, it is obvious that the observed stability is due to kinetic inertness, rather than thermodynamic stability.

Calculations and in situ XPS measurements in contact with $\mathrm{Li}$ metal revealed that lithiation of LGPS already starts at $1.71 \mathrm{vs} \mathrm{Li} /$ $\mathrm{Li}^{+}$, with the final equilibrium phases in contact with $\mathrm{Li}$ metal being $\mathrm{Li}_{15} \mathrm{Ge}_{4}, \mathrm{Li}_{3} \mathrm{P}$ and $\mathrm{Li}_{2} \mathrm{~S}[79,80]$. Similar decomposition potentials in the cathodic limit are observed for other sulfide SEs such as $\mathrm{Li}_{7} \mathrm{P}_{3} \mathrm{~S}_{11}$ and the Argyrodites. To learn about the "practical" ESW it is therefore crucial to perform long-term electrochemical measurements in contact with $\mathrm{Li}$ and to analyze the reaction products at the $\mathrm{SE}$ - lithium interface, which are inaccessible when doing cyclic voltammetry scans only.

The oxidation stability of LGPS is limited to $2.14 \mathrm{~V}$, with the final delithiation products being $\mathrm{P}_{2} \mathrm{~S}_{5}, \mathrm{GeS}_{2}$ and $\mathrm{S}$. Generally, all sulfide SEs are oxidized between 2 and $2.5 \mathrm{~V}$ to form sulfur with relatively high decomposition energies, thus indicating that the observed large ESW of up to more than $5 \mathrm{~V}$ is purely kinetic in origin. In fact, most decomposition products at high voltages are electronically insulating and/or are only formed at large overpotentials (especially when the formation of gaseous products is involved), such that the sluggish kinetics of the decomposition reactions may provide a larger than the thermodynamic ESW.

In principle, a SE can be protected by the formation of a stable interphase composed of the decomposition products, which may act as a solid-electrolyte interphase (SEI). As outlined in Part I and sketched in Fig. 4(c) and Fig. 7(b) this interphase can act as a buffer between the high Li chemical potential $\mu_{\mathrm{Li}}$ of the anode and the low chemical potential $\mu_{\mathrm{Li}}$ at the reduction potential (cathodic stability limit) of the SE. Depending on the decomposition products formed and its morphology, the interphase can passivate the SE and explain the compatibility observed for certain SEs in contact with Li metal. In LGPS, however - similar to the situation in LISICON, LLTO, LATP and other SEs - the cathodic decomposition products include the electronically conducting compound $\mathrm{Li}_{15} \mathrm{Ge}_{4}$ which may - depending on its distribution - make the formation of a thin stationary SEI layer difficult. Although in principle LSiPS faces similar issues, it has been reported that the properties of the passivation layer in LSiPS are very different from those in LGPS. It has been speculated that this might be due to the more insulating silicide formed. [63].

To place the ionic conductivity and stability of LGPS into context, Table 1 provides an overview of relevant oxide, oxynitride and sulfide SEs, their experimentally observed conductivities as well as their chemical stabilities and phase equilibria at 0 and $5 \mathrm{~V}$, according to a recent study by Mo and coworkers as well as selected experimental data.
These data clearly indicate that none of the currently discussed SEs has an electrochemical (thermodynamic) stability window which is larger than $3 \mathrm{~V}$, in contrast to many (ionic) liquid electrolytes. The highest stability window is found in LLZO which is particularly stable against reduction $\left(0.05 \mathrm{~V}\right.$ vs Li$/ \mathrm{Li}^{+}$to $2.91 \mathrm{~V}$ vs Li/ $\left./ \mathrm{Li}^{+}\right)$, and the lowest stability window found for LiPON, irrespective of its nitrogen content. While the highest oxidation stabilities are observed for the NASICON-type oxides LATP and LAGP (4.21 and 4.28 V, respectively), all sulfide SEs are prone to oxidation already between 2 to $2.5 \mathrm{~V}$ to form $\mathrm{S}$, without any exception. At the same time, however, LATP and LAGP are even more prone to reduction than the sulfide SEs.

The chemical stability with respect to possible high voltage cathode materials has been investigated for the LGPS $\mathrm{Li}_{x} \mathrm{CoO}_{2}$ interface. While oxide SEs such as LLTO, LLZO and LATP have only small decomposition free energies or are even thermodynamically stable against $\mathrm{Li}_{x} \mathrm{CoO}_{2}$, LGPS and other sulfide SEs are thermodynamically highly unstable against $\mathrm{LiCoO}_{2}$ [81]. Expected decomposition products include $\mathrm{Co}_{9} \mathrm{~S}_{8}$ (next to $\mathrm{Li}_{2} \mathrm{~S}, \mathrm{Li}_{2} \mathrm{SiO}_{4}, \mathrm{Li}_{3} \mathrm{PO}_{4}, \mathrm{Li}_{4} \mathrm{GeO}_{4}$ ), which is electronically conducting and therefore detrimental to the long-term stability of the SE-electrode interface.

Since the electrochemical stability window of LGPS is tiny (1.7-2.14 V vs Li/ $/ \mathrm{Li}^{+}$) and, therefore, LGPS is expected to be reactive with respect to essentially all high-voltage cathode materials, the application of an artificial coating layer at the cathode as currently done for LGPS seems mandatory. These coating layers cannot only prevent the formation of uncontrolled decomposition products at the SE-electrode interface and the formation of electronically conducting interphases, but they can also mitigate the formation of interfacial space-charge layers. Possible coating layers - typically deposited by ALD to ensure conformal coating and thin layer thickness - include $\mathrm{LiNbO}_{3}, \mathrm{LiTaO}_{3}$, $\mathrm{Li}_{4} \mathrm{Ti}_{5} \mathrm{O}_{12}$, or $\mathrm{Li}_{3} \mathrm{PO}_{4}$ [81]. Although these layers show good stability with respect to $\mathrm{Li}_{x} \mathrm{CoO}_{2}$ and the tendency for decomposition of LGPS is lower, such artificial protection layers lack the flexibility and the self-healing ability of in-situ formed SEs. In other words, long-term chemical compatibility of sulfide SEs with the coating layer and the requirement for high Li conductivity across the interface remains a grand challenge.

\section{(iii) Mechanical stability}

A big asset of sulfide SEs is their mechanical softness, which is in stark contrast to the brittleness of their oxide counterparts which exhibit often high elastic moduli. This softness is particularly useful to establish a conformal, cohesive and dense interface with the electrode that is mechanically stable also under conditions of prolonged operation. Whereas oxide SEs have to be sintered at high temperatures to mitigate grain-boundary and charge transfer resistances arising from non-ideal and nonconformal contact between the grains and with the electrode, 
(a)

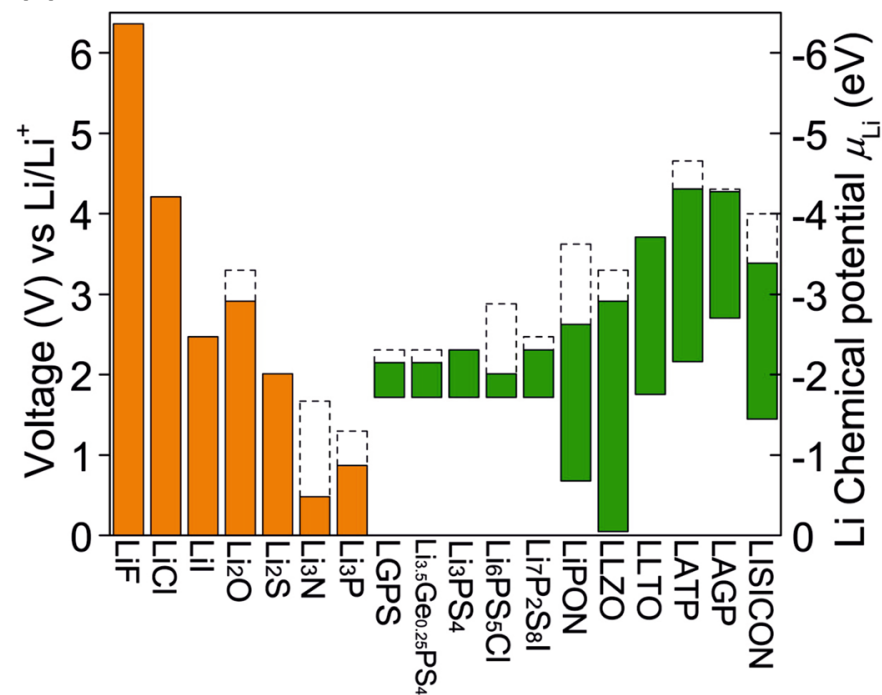

(b)



Fig. 7 (a) Electrochemical window (solid colored bars) of representative solid electrolytes and common binary decomposition products formed in contact with Li metal. The oxidation potential for complete delithiation is indicated by the dashed lines. (b) Schematic showing the change of the $\mathrm{Li}$ chemical potential $\mu_{\mathrm{Li}}$ (black line), the electrochemical potentials of the

sulfides offer the advantage of easy processing to establish good interfacial contact. A recent study by Tatsumisago and coworkers showed that glassy thiophosphate SEs are amenable to room-temperature pressure sintering due to their moderate Young's moduli in the range of $18-25 \mathrm{GPa}$, which is about one third of that of an oxide glass [89]. In other words, due to their softness, the particle size and morphology of sulfides can be much more easily controlled than in oxides, even without sintering at high temperatures. Thus, pellets made from sulfide SEs may be compressed and compacted at elevated pressures to yield high densities of $>90 \%$ and small void volumes already at low temperatures by cold pressing, which is beneficial for providing efficient charge percolation between the SE grains and the electrode.

An interesting question in this context is to what extent the high-pressure treatment is applicable also to crystalline sulfide SEs such as LGPS, without inducing severe structural collapse of the LGPS lattice. A realistic scenario is that pressure-induced amorphization may result in the (partial) formation of glassy phases, leading to glass-ceramics with high-conductivity crystalline domains embedded in amorphous domains with potentially moderate conductivity. In optimistic scenarios, the resulting more dense and compliant morphology, leading to better interfacial contact and hence lower charge transfer resistances, lower overvoltages and less capacity fading, may even overcompensate (moderate) losses in conductivity.

\section{(iv) Thermal properties and reactivity}

Without doubt, the thermal stability of most SE is significantly higher than that of their liquid counterparts. ionic $\left(\tilde{\mu}_{L^{+}}\right.$, blue line $)$and electronic $\left(\tilde{\mu}_{e^{-}}\right.$, red line $)$charge carriers at the electrode - electrolyte interface, modified by the presence of a solid electrolyte interphase (orange). Adapted from Ref. [79]. The reader should note that electronic equilibrium and hence component equilibrium is usually not established throughout the electrolyte

This holds especially true for oxide SEs, but also LGPS and other sulfide SE were found to be thermally stable up to $400-550{ }^{\circ} \mathrm{C}$ and therefore beyond practically relevant temperatures for battery operation [90]. This apparent thermal stability however needs to be put into perspective: As suggested by a T-dependent X-ray diffraction study [71] and theoretical calculations [77], LGPS may not be intrinsically stable across the entire relevant temperature range between RT and $300{ }^{\circ} \mathrm{C}$. In particular, the nominal stability window may be different (likely smaller) for different solid solution members than currently available experimental data suggest [90]. Possible complications include the transformation of LGPS into orthorhombic thio-LISICON phases with different stoichiometry and the concomitant formation of side phases, as already observed for LGPS by the formation of $\mathrm{Li}_{4} \mathrm{P}_{2} \mathrm{~S}_{6}$ between 300 and $400{ }^{\circ} \mathrm{C}$ [71]. As the authors of that study point out, however, it is well conceivable that the formation of decomposition products commences already near room temperature, which is particularly critical for the long-term operation of all-solid-state batteries based on LGPS. There is therefore a clear need for further investigations into the thermal properties of LGPS-type materials.

Generally, the requirements for safe operation of SEs are multifaceted. Besides thermal stability and non-flammability as true for most SEs, chemical and electrochemical inertness as discussed above, resistance against dendrite formation as well as the absence of toxic by-products in case of battery damage are important criteria, just to name a few. For LGPS the latter seems to be particularly critical, as most sulfides are extremely air-sensitive and prone to fast hydrolysis when 


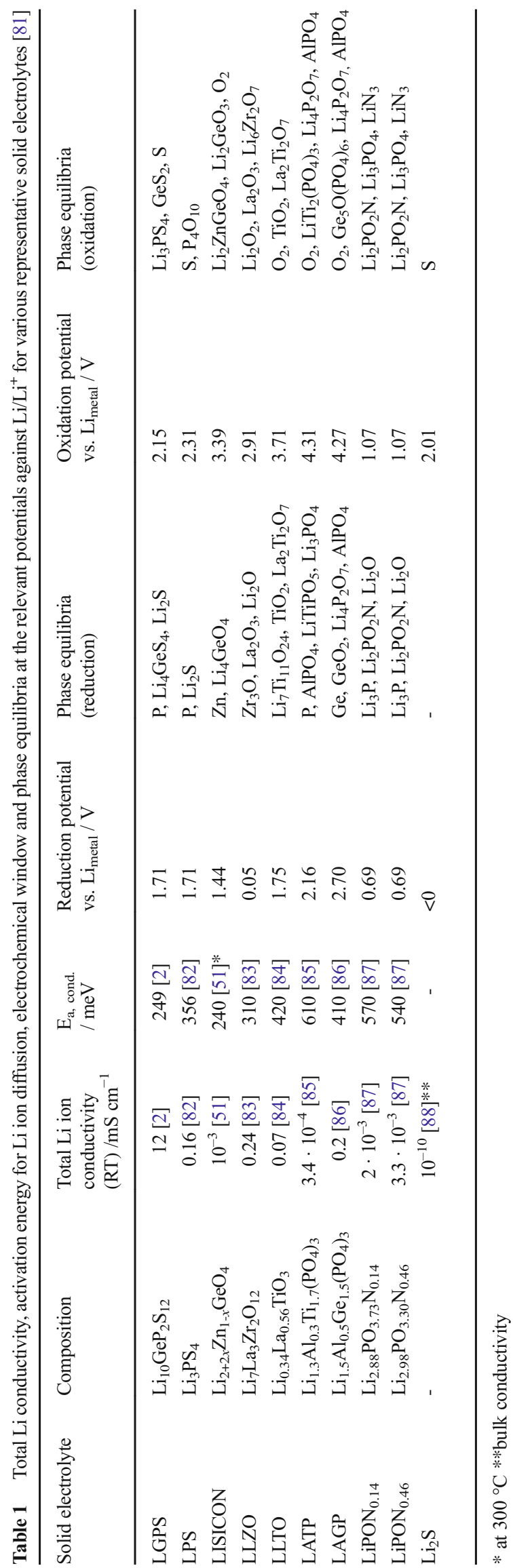

exposed to humid air, yielding $\mathrm{H}_{2} \mathrm{~S}$, a highly toxic volatile, as a decomposition product.

Although long-term and safe operation of LGPS-type SEs with minimal loss of capacity is hard to envision at present, the right combination of materials and clever engineering of the interfaces, along with ultra-thin film battery geometries and proper packaging, may eventually help to unfold the full potential of ultrafast SEs such as LGPS for all-solid-state batteries.

\subsection{Solid electrolytes beyond LGPS: New materials developments}

As far as all-solid-state cells are concerned, the development of "fast" and at the same time stable Li solid electrolytes that can be fashioned into compliant thin films and device geometries is a key prerequisite. Therefore, the search for new and earth-abundant solid electrolytes with improved properties should be at the heart of research directed at practicable allsolid-state cells. Along these lines, we mention the recent discovery of a layered, crystalline superionic Li conductor in the system $\mathrm{Li}-\mathrm{Sn}-\mathrm{S}-\mathrm{Li}_{2} \mathrm{Sn}_{2} \mathrm{~S}_{5}$, a Li-depleted version of $\mathrm{Li}_{2} \mathrm{SnS}_{3}$ (Fig. 8) - which shows Li conductivities competitive with those of LGPS $\left(\sigma_{\mathrm{NMR}}=9 \times 10^{-3} \mathrm{~S} / \mathrm{cm}\right.$ at RT $)$, whilst being reasonably stable under ambient conditions [5].

Goodenough and co-workers recently presented a new $\mathrm{Li}$ solid electrolyte with a defective cubic antiperovskite structure, which is easy to make, scalable and amenable to hot pressing, yielding $100 \%$ dense pellets already at $350{ }^{\circ} \mathrm{C}$. The fluorine-doped version of $\mathrm{Li}_{2}(\mathrm{OH}) \mathrm{Cl}$ with approximate composition $\mathrm{Li}_{2}(\mathrm{OH})_{0.9} \mathrm{~F}_{0.1} \mathrm{Cl}$ is stable on contact with metallic $\mathrm{Li}$ and shows an extremely wide ESW extending to $9 \mathrm{~V} \mathrm{vs}^{+}$/ Li. While Li conductivities of $3.5 \times 10^{-5} \mathrm{~S} / \mathrm{cm}$ were determined in the dry state, several orders of magnitude higher conductivities were observed when exposed to humid air, albeit at the expense of electrochemical stability [92].

A new family of potentially fast Li solid electrolytes based on phosphidosilicates in the system Li-Si-P was recently discovered by the groups of Johrendt and Fässler [93, 94]. $\mathrm{Li}_{2} \mathrm{SiP}_{2}$ and $\mathrm{LiSi}_{2} \mathrm{P}_{3}$ feature interpenetrating $3 \mathrm{D}$ networks of corner-sharing $\mathrm{SiP}_{4}$ supertetrahedra while the Li ions are located in the cavities and channels of the supertetrahedral networks. In contrast, $\mathrm{Li}_{8} \mathrm{SiP}_{4}$ is composed of isolated $\mathrm{SiP}_{4}$ tetrahedra surrounded by $\mathrm{Li}$ atoms and shows structural analogies to the cubic antifluorite structure type. Li transport in $\mathrm{Li}_{8} \mathrm{SiP}_{4}$ and $\mathrm{Li}_{2} \mathrm{SiP}_{2}$ was studied by electrochemical impedance spectroscopy, revealing grain-boundary limited ionic conductivities between $1.15(7) \times 10^{-6} \mathrm{~S} / \mathrm{cm}$ at $0{ }^{\circ} \mathrm{C}$ and 1.2(2) $\times 10^{-4} \mathrm{~S} / \mathrm{cm}$ at $75{ }^{\circ} \mathrm{C}$ for $\mathrm{Li}_{8} \mathrm{SiP}_{4}$ and between $6.1(7)$ $\times 10^{-8} \mathrm{~S} / \mathrm{cm}$ at $0{ }^{\circ} \mathrm{C}$ and $6(1) \times 10^{-6} \mathrm{~S} / \mathrm{cm}$ at $75^{\circ} \mathrm{C}$ for $\mathrm{Li}_{2} \mathrm{SiP}_{2}$ [94]. These few examples already give a flavor of the large range of novel Li solid electrolytes yet to be uncovered, and at the same time highlight the challenges and bottlenecks associated with such endeavors. 


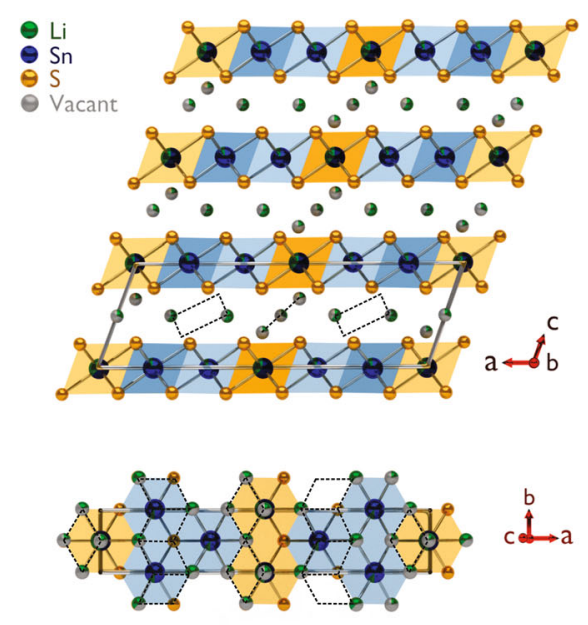

Fig. 8 Left: Crystal structure of the layered Li superionic conductor $\mathrm{Li}_{2} \mathrm{Sn}_{2} \mathrm{~S}_{5}$, viewed along (top) and perpendicular to the $\mathrm{SnS}(\mathrm{Li})$ layers. The interlayer Li content in the monoclinic structure is depleted as compared to the fully lithiated relative $\mathrm{Li}_{2} \mathrm{SnS}_{3}$, resulting in an ordersof-magnitude higher Li conductivity [91]. The 2D Li trajectories as calculated by TOPOS are indicated by dotted lines. Right: ${ }^{7} \mathrm{Li}$ Pulsed

\section{Conclusion}

In view of the above given discussion, the realization of all-solidstate batteries is extremely challenging if high power applications are concerned. For low power batteries all-solid-state thin film systems seem appropriate, but face serious problems as well.

Considering the possibility to combine advantages of solid and liquid state, solid-liquid composites may be a pertinent way out, the more so since materials such as soggy-sand electrolytes or polyelectrolytes have proven to exhibit not only favorable mechanical properties, but also very high $\mathrm{Li}$ or $\mathrm{Na}$ transport numbers. However, as they still contain liquid electrolytes, they would not fully overcome the safety issues.

As far as all-solid-state cells are concerned, four rather recently published papers shall be emphasized that offer a glimmer of hope for their realization:

Kanno's group reported cyclable batteries based on the new LGPS-type Li electrolyte with nominal composition $\mathrm{Li}_{9.54} \mathrm{Si}_{1.74} \mathrm{P}_{1.44} \mathrm{~S}_{11.7} \mathrm{Cl}_{0.3}$ in a $\mathrm{LiCoO}_{2} /$ solid electrolyte/Li cell configuration using graphite as anode material. They obviously achieved a sufficient passivation and hence kinetically stable situation, which was demonstrated by an excellent cycling performance at a high current density of $18 \mathrm{C}$ at $100{ }^{\circ} \mathrm{C}$ [6].

Wachsman's group reported a solid-state Li battery using the thermodynamically stable garnet as electrolyte. They did not observe dendrite growth, which they attributed to a homogeneous wetting of metallic lithium in contact with the garnet electrolyte surface, mediated by an ultrathin, conformal $\mathrm{Al}_{2} \mathrm{O}_{3}$ ALD-coating [48]. They also report mechanically well working contacts that they attribute to the built-in pore structure. Likewise, Rupp's group [95] demonstrated that by engineering
Bulk properties Grain boundary effects

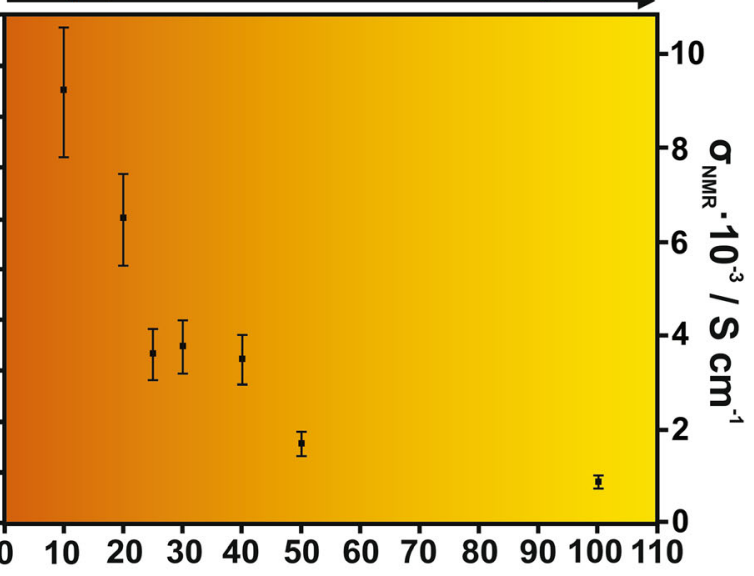

$\Delta / \mathrm{ms}$

Field Gradient (PFG) NMR of $\mathrm{Li}_{2} \mathrm{Sn}_{2} \mathrm{~S}_{5}$, showing the diffusion coefficients $D_{\mathrm{NMR}}$ determined at various diffusion times $\Delta$. $D_{\mathrm{NMR}}$ increases with decreasing diffusion times $\Delta$, indicating a cross-over from the grain boundary-limited to the intrinsic regime where bulk diffusion dominates (reproduced with permission of [5])

the interface between the nanoporous garnet solid electrolyte $c$ $\mathrm{Li}_{6.25} \mathrm{Al}_{0.25} \mathrm{La}_{3} \mathrm{Zr}_{2} \mathrm{O}_{12}$ and a nanograined $\mathrm{Li}_{4} \mathrm{Ti}_{5} \mathrm{O}_{12}$ anode significantly lowered impedances and improved capacities were achieved. This work highlights the important role of morphology engineering in reducing the interfacial resistance between electrode and solid electrolytes, which remains one of the most severe bottlenecks in the development of all-solid-state cells.

Finally, Masquelier's group published elegant work using NASICON electrolytes and and sodium vanadium phosphate (NVP) as both positive and negative electrodes, hence arriving at an all NASICON-structured cell [96]. Nevertheless, in spite of the favorable structural preconditions for forming wellbehaved contacts, they had to use elevated operation temperatures to achieve a good performance.

These reports may be considered as pars pro toto for promises and difficulties in this exciting area.

Acknowledgements Open access funding provided by Max Planck Society. BVL thanks Sascha Harm, Tanja Holzmann and Claudia Kamella for their assistance in editing the text and for preparing tables and artworks for this manuscript.

Open Access This article is distributed under the terms of the Creative Commons Attribution 4.0 International License (http:// creativecommons.org/licenses/by/4.0/), which permits unrestricted use, distribution, and reproduction in any medium, provided you give appropriate credit to the original author(s) and the source, provide a link to the Creative Commons license, and indicate if changes were made.

\section{References}

1. J. Janek, W.G. Zeier, Nature Energy 1, 16141 and refs. therein (2016) 
2. N. Kayama, K. Homma, Y. Yamakawa, R. Kanno, M. Yonemura, T. Kamiyama, Y. Kato, S. Hama, K. Kawamoto, A. Mitsui, Nat. Mater. 10, 682 (2011)

3. A. Kuhn, O. Gerbig, C. Zhu, F. Falkenberg, J. Maier, B.V. Lotsch, Phys. Chem. Chem. Phys. 16, 14669 (2014)

4. P. Bron, S. Johansson, K. Zick, J. Schmedt, a.d. Günne, S. Dehnen, B. Roling. J. Am. Chem. Soc. 135, 15694 (2013)

5. T. Holzmann, L.M. Schoop, M.N. Ali, I. Moudrakovski, G. Gregori, J. Maier, R.J. Cava, B.V. Lotsch, Energy Environ. Sci. 9, $2578(2016)$

6. Y. Kato, S. Hori, T. Saito, M. Hirayama, A. Mitsu, M. Yonemura, H. Iba, R. Kanno, Nat. Energy 1, 16030 (2016)

7. J. O'M Bockris, A.K.V. Reddy, Modern electrochemistry (Plenum Press, NewYork, 1970)

8. G. Kortüm, Treatise on electrochemistry (Elsevier, Amsterdam, 1965)

9. B.B. Owens, J.E. Oxley, A.F. Sammells, In Solid Electrolytes, ed. By S. Geller (Springer, Berlin, 1977), p. 67

10. A. Rabenau, Solid State Ionics 6, 277 (1982)

11. U. von Alpen, A. Rabenau, G.H. Talat, Appl. Phys. Lett. 30, 621 (1977)

12. C.A. Beevers, M.A.R. Ross, Z. Krist. 95, 59 (1937)

13. J.T. Kummer, Prog. Solid State Chem. 7, 141 (1972)

14. J.H. Kennedy, In Solid electrolytes, Vol. 21, ed. By S. Geller (Springer, Berlin, 1977), p.105

15. T. Takahashi, O. Yamamoto, S. Yamada, S. Hayashi, J. Electrochem. Soc. 126, 1654 (1979)

16. G. Farrington, B. Dunn, Solid State Ionics 7, 287 (1982)

17. J.B. Goodenough, H.Y.-P. Hong, J.A. Kafalas, Mater. Res. Bull. 11, 203 (1976)

18. J.P. Boilot, P. Colomban, G. Collin, Solid State Ionics 28-30, 403 (1988)

19. H. Kohler, H. Schultz, O. Melnikov, Mater. Res. Bull. 18, 589 (1983)

21. J. Maier, U. Warhus, J. Chem. Thermodyn. 18, 309 (1986)

21. K.D. Kreuer, H. Kohler, J. Maier, In High conductivity ionic conductors: Recent Trends and Applications, ed. By T. Takahashi (World Scientific, Singapore, 1989) p. 242

22. P.G. Dickens, M.S. Whittingham, Q. Rev. 22, 30 (1968)

23. M.S. Whittingham, R.A. Huggins, J. Chem. Phys. 54, 414 (1971)

24. M.S. Whittingham, J. Electrochem. Soc. 125, 315 (1976)

25. M.S. Whittingham, Prog. Solid State Chem. 12, 41 (1978)

26. R.A. Huggins, J. Power Sources 81-82, 13 (1999)

27. K. Mizushima, P.C. Jones, P.J. Wiseman, J.B. Goodenough, Mater. Res. Bull. 15, 783 (1980)

28. C. Sun, S. Rajasekhara, J.B. Goodenough, J. Am. Chem. Soc. 133, $2132(2011)$

29. R. Yazami, P.H. Touzain, J. Power Sources 9, 365 (1983)

30. R. Fong, U. von Sacken, J.R. Dahn, J. Electrochem. Soc. 137, 2009 (1990)

31. E. Peled, J. Electrochem. Soc. 126, 2047 (1979)

32. D. Aurbach, J. Power Sources 89, 206 (2000)

33. P. Knauth, Solid State Ionics 180, 911 (2009)

34. A. Patil, V. Patil, J.W. Choi, J.S. Kim, S.J. Yoon, J. Nanosci. Nanotechnol. 17, 29 (2017)

35. J. Maier, Physical Chemistry of Ionic Materials. Ions and Electrons in Solids (Wiley, Ltd, Chichester, 2004)

36. J. Maier, X. Guo, J. Electrochem. Soc. 148, E121 (2001)

37. J. Maier, Prog. Solid State Chem. 23, 171 (1995)

38. H. Maekawa, R. Tanaka, T. Sato, Y. Fujimaki, T. Yamamura, Solid State Ionics 175, 281 (2004)

39. C.C. Liang, J. Electrochem. Soc. 120, 1298 (1973)

40. O. Yamamoto, Y. Takedo, R. Kanno, Kagaku 38, 387 (1983)

41. J. Maier, Chem. Mater. 26, 348 (2014)

42. J. Maier, Electrochim.Acta 129, 21 (2014)

43. J. Fleig, J. Maier, J. Electroceram. 1, 73 (1997)
44. M. Gaberscek, J. Moskon, B. Erjavec, R. Dominko, J. Jamnik, Electrochem. Solid-State Lett. 11, A170 (2008)

45. Y.E. Wang, W.D. Richards, L.J. Miara, J.C. Kim, G. Ceder, Materials Design Guidelines for All Solid-State Batteries, Meeting Abstracts No. 2, The Electrochemical Society (2016)

46. R. Raj, J. Wolfenstine, J. Power Sources 343, 119 (2017)

47. W.D. Kingery, H.K. Bowen, D.R. Uhlmann, An introduction to ceramics (John Wiley \& Sons, Ltd., New York, 1976)

48. X. Han, Y. Gong, K. Fu, X. He, G.T. Hitz, J. Dai, A. Pearse, B. Liu, H. Wang, G. Rubloff, Y. Mo, V. Thangadurai, E.D. Wachsman, L. $\mathrm{Hu}$, Nat. Mater. (2016). doi:10.1038/nmat4821

49. W. Luo, Y. Gong, Y. Zhu, K.K. Fu, J. Dai, S.D. Lacey, C. Wang, B. Liu, X. Han, Y. Mo, E.D. Wachsman, L. Hu, J. Am. Chem. Soc. 138, 12258 (2016)

50. Y. Seino, T. Ota, K. Takada, A. Hayashi, M. Tatsumisago, Energy Environ. Sci. 7, 627 (2014)

51. H.Y.-P. Hong, Mater. Res. Bull. 13, 117 (1978)

52. P.G. Bruce, A.R. West, J. Electrochem. Soc. 130, 662 (1983)

53. M. Ito, Y. Inaguma, W.-H. Jung, L. Chen, T. Nakamura, Solid State Ionics 70/71, 203 (1994)

54. A.G. Belous, G.N. Novitskaya, S.V. Polyanetskaya, Y.I. Gornikov, Russ. J. Inorg. Chem. 32, 156 (1987)

55. J. Emery, J.-Y. Buzaré, O. Bohnke, J.-L. Fourquet, Solid State Ionics 99, 41 (1997)

56. O. Bohnke, J. Emery, J.-L. Fourquet, Solid State Ionics 158, 119 (2003)

57. H. Aono, E. Sugimoto, Y. Sadaoka, N. Imanaka, G. Adachi, J. Electrochem. Soc. 136, 590 (1989)

58. V. Thangadurai, W. Weppner, J. Am. Ceram. Soc. 88, 411 (2005)

59. V. Thangadurai, W. Weppner, Adv. Funct. Mater. 15, 107 (2005)

60. V. Thangadurai, D. Pinzaru, S. Narayanan, A.K. Baral, J. Phys. Chem. Lett. 6, 292 (2015)

61. J.H. Kennedy, Y. Yang, J. Solid State Chem. 69, 252 (1987)

62. S. Kondo, K. Takada, Y. Yamaura, Solid State Ionics 53-56, 1183 (1992)

63. R. Kanno, M. Murayama, J. Electrochem. Soc. 148, A742 (2001)

64. M. Murayama, R. Kanno, M. Irie, S. Ito, T. Hata, N. Sonoyama, Y. Kawamoto, J. Solid State Chem. 168, 140 (2002)

65. S.-T. Kong, H.-J. Deiseroth, C. Reiner, Ö. Gün, E. Neumann, C. Ritter, D. Zahn, Chem. Eur. J. 16, 2190 (2010)

66. O. Pecher, S.-T. Kong, T. Goebel, V. Nickel, K. Weichert, C. Reiner, H.-J. Deiseroth, J. Maier, F. Haarmann, D. Zahn, Chem. Eur. J. 16, 8347 (2010)

67. H.-J. Deiseroth, S.-T. Kong, H. Eckert, J. Vannahme, C. Reiner, T. Zaiß, M. Schlosser, Angew. Chem. Int. Ed. 47, 755 (2008)

68. R.P. Rao, S. Adams, Phys. Status Solidi A 208, 1804 (2011)

69. S. Boulineau, M. Courty, J.-M. Tarascon, V. Viallet, Solid State Ionics 221, 1 (2012)

70. A. Kuhn, J. Köhler, B.V. Lotsch, Phys. Chem. Chem. Phys. 15, $11620(2015)$

71. D.A. Weber, A. Senyshyn, K.S. Weldert, S. Wenzel, W. Zhang, R. Kaiser, S. Berendts, J. Janek, W.G. Zeier, Chem. Mater. 28, 5905 (2016)

72. O. Kwon, M. Hirayama, K. Suzuki, Y. Kato, T. Saito, M. Yonemura, T. Kamiyama, K. Kanno, J. Mater. Chem. A 3, 438 (2015)

73. Y. Wang, W.D. Richards, S.P. Ong, L.J. Miara, J.C. Kim, Y. Mo, G. Ceder, Nat. Mater. 14, 1026 (2015)

74. Y. Kato, R. Saito, M. Sakano, M. Hirayama, R. Kanno, J. Power Sources 271, 60 (2014)

75. K. Yang, J. Dong, L. Zhang, Y. Li, L. Wang, J. Am. Ceram. Soc. 98, $3831(2015)$

76. P. Zhou, J. Wang, F. Cheng, F. Li, J. Chen, Chem. Commun. 52, 6091 (2016)

77. S.P. Ong, Y. Mo, W.D. Richards, L. Miara, H.S. Lee, G. Ceder, Energy Environ. Sci. 6, 148 (2013) 
78. S. Kazemiabnavi, Z. Zhang, K. Thornton, S. Banerjee, J. Phys. Chem. B 120, 5691 (2016)

79. Y. Zhu, X. He, Y. Mo, ACS Appl. Mater. Interfaces 7, 23685 (2015)

80. S. Wenzel, S. Randau, T. Leichtweiß, D.A. Weber, J. Sann, W.G. Zeier, J. Janek, Chem. Mater. 28, 2400 (2016)

81. Y. Zhu, X. He, Y. Mo, J. Mater. Chem. A 4, 3253 (2016)

82. Z. Liu, W. Fu, E.A. Payzant, X. Yu, Z. Wu, N.J. Dudney, J. Kiggans, K. Hong, A.J. Rondinone, C. Liang, J. Am. Chem. Soc. 135, 975 (2013)

83. R. Murugan, V. Thangadurai, W. Weppner, Angew. Chem. Int. Ed. 46, 7778 (2007)

84. Y. Inaguma, C. Liquan, M. Itoh, T. Nakamura, T. Uchida, H. Ikuta, W. Wakihara, Solid State Commun. 86, 689 (1993)

85. N.V. Kosova, E.T. Devyatkina, A.P. Stepanov, A.L. Buzlukov, Ionics 14, 303 (2008)

86. C.R. Mariappan, C. Yada, F. Rosciano, B. Roling, J. Power Sources 196, $6456(2011)$

87. X. Yu, J.B. Bates, G.E. Jellison, F.X. Hart, J. Electrochem. Soc. 144, 524 (1997)

88. I. Seo, S.W. Martin, ECS Trans. 28, 287 (2010)
89. A. Sakuda, A. Hayashi, M. Tatsumisago, Sci.Rep. 3, 2261 (2013)

90. S. Hori, M. Kato, K. Suzuki, M. Hirayama, J. Am. Ceram. Soc. 98, $3352(2015)$

91. J.A. Brant, D.M. Massi, N.A.W. Holzwarth, J.H. MacNeil, A.P. Douvalis, T. Bakas, S.W. Martin, M.D. Gross, J.A. Aitken, Fast lithium ion conduction in Li SnS: synthesis, physicochemical characterization, and electronic structure. Chem. Mater. 27(1), 189-196 (2015)

92. Y. Li, W. Zhou, S. Xin, S. Li, J. Zhu, X. Lî, Z. Cui, Q. Jia, J. Zhou, Y. Zhao, J.B. Goodenough, Angew. Chem. Int. Ed. 55, 9965 (2016)

93. A. Haffner, T. Bräuniger, D. Johrendt, Angew. Chem. Int. Ed. 55, 13585 (2016)

94. L. Toffoletti, H. Kirchhain, J. Landesfeind, W. Klein, L. van Wüllen, H.A. Gasteiger, T.F. Fässler, Chem. Eur. J. 22, 17635 (2016)

95. J. van den Broek, S. Afyon, J.L.M. Rupp, Adv. Energy Mater. 6, $1600736(2016)$

96. F. Lalère, J.B. Leriche, M. Courty, S. Boulineau, V. Viallet, C. Masquelier, V. Seznec, J. Power Sources 247, 975 (2014) 